\title{
Impact of Agricultural Inputs on Groundwater Pollution in Off-Season Rice Farming in the Pic of Sindou Perimeter in Burkina Faso
}

\author{
Bama Nati Aïssata Delphine ${ }^{*}$, Barké Guida Habiba², Koita Mahamadou², Niang Dial1, \\ Yacouba Hamma² \\ ${ }^{1}$ Plant Production Department, Institute for the Environment and Agricultural Research, INERA, Ouagadougou, Burkina Faso \\ ${ }^{2}$ Hydro-Systems and Agriculture Water Laboratory, International Institute for Water and Environmental Engineering, \\ Ouagadougou, Burkina Faso \\ Email: *nati_aissata@yahoo.fr, *nati.aissata@gmail.com
}

How to cite this paper: Delphine, B.N.A., Habiba, B.G., Mahamadou, K., Dial, N. and Hamma, Y. (2020) Impact of Agricultural Inputs on Groundwater Pollution in Off-Season Rice Farming in the Pic of Sindou Perimeter in Burkina Faso. Journal of Water Resource and Protection, 12, 381-388. https://doi.org/10.4236/jwarp.2020.125022

Received: February 28, 2020

Accepted: April 20, 2020

Published: April 23, 2020

Copyright $\odot 2020$ by author(s) and Scientific Research Publishing Inc. This work is licensed under the Creative Commons Attribution International License (CC BY 4.0).

http://creativecommons.org/licenses/by/4.0/

\begin{abstract}
Burkina Faso, an $80 \%$ agricultural country, today copes the massive use of agricultural inputs to boost productivity. However, these pesticides are sources of pollution of water resources. This is how, the objective of this work was to take stock of the inputs used on the Pic of Sindou rice perimeter and to characterize the vulnerability of the aquifer to these products. The study took place from February to September 2019, where two hundred farmers of the perimeter were investigated on the type and quantity of fertilizers and pesticides used in off-season rice farming activities. The DRASTIC method was used to map the vulnerability of the groundwater resource to these pollutants. Producers use NPK and Urea at $90 \%$ and $10 \%$ to the organic manure as fertilizers, and herbicides and insecticides with the actives ingredient are Glyphosate, Dimethoate and 2.4 D amine salt. The vulnerability to agricultural pollution of the aquifer remains low, but the risk of contamination from pesticides remains possible.
\end{abstract}

\section{Keywords}

Groundwater, Pesticide, Herbicide, Pollution, Off Season Rice Growing

\section{Introduction}

Located in West Africa, Burkina Faso is a landlocked and agricultural country at $80 \%$ [1]. Agriculture represents the main source of income for more than $80 \%$ of the working population and remains the main pillar of food security in the country with a contribution of around $35 \%$ to Gross Domestic Product [1]. 
However, this rainfed agriculture nowadays deals with effects of climate variability, weeds, diseases and pests which cause considerable damage [2]. To cope with this situation, phytosanitary products are used massively by small farmers to control pests and weeds [3]. This massive use of agricultural inputs is potential source of pollution of water resources [4] [5] [6] [7]. While these inputs have stimulated rice production, they have also contributed to increasing the risk of threats to both ground and surface water resources [8] [9]. The region of Cascades in Burkina Faso is full of the enormous potential of surface and groundwater resources. Indeed, the plain of Niofila where the Pic of Sindou perimeter is located is crossed by the stream of the eastern Léraba, a tributary of the river Comoé. In addition, there is also the sedimentary zone which abounds in important reservoir of water with numerous springs which provide a basic flow to the main rivers. However, in this region nowadays, farmers use inputs uncontrollably to fight against pests like everywhere else. In this condition, the protection of these water resources becomes a necessity. Thus, the objective of this study was to characterize the vulnerability of the aquifer to pollution linked to off-season rice farming on Pic of Sindou perimeter with a view to the best management of agricultural inputs.

\section{Material and Method}

\subsection{Presentation of the Study Area}

The Pic of Sindou perimeter site $\left(10^{\circ} 39^{\prime} 31^{\prime \prime}\right.$ North and $5^{\circ} 9^{\prime} 57^{\prime \prime}$ West $)$ is part of the spacious Niofila-Douna flood plain in the eastern Leraba watershed, beneath of COMOE watershed. The geological formations consist of the basement area (84\% of the watershed) with discontinuous aquifers and of low productivity, and, from a sedimentary area to the north containing a large reservoir of groundwater, as evidenced by the numerous springs that provide a basic flow to the main rivers [10]. The soils of the plain are predominantly clay. The perimeter, around 320 ha is dedicated to growing rice during rainy season and exploited by the villages of Sindou, Douna and Niofila. During the off-season, the perimeter is mainly planted with rice with a little market gardening and a last part is not exploited, given the insufficiency of the water resource. The water requirements for off-season irrigation come from withdrawals from the four springs present on the perimeter through earth channels made by producers for irrigation in the off-season and from drainage in the event of a flood in rainy season (Figure 1).

\subsection{Characterization of Agricultural Inputs}

The diagnosis of the inputs used in the rice growing in the off-season was carried out in the form of a survey administered to 200 farmers in the area during the month of May 2019. The data collected made it possible to highlight the types and quantity of fertilizers used, and pesticides according to their toxicity and active ingredients. 


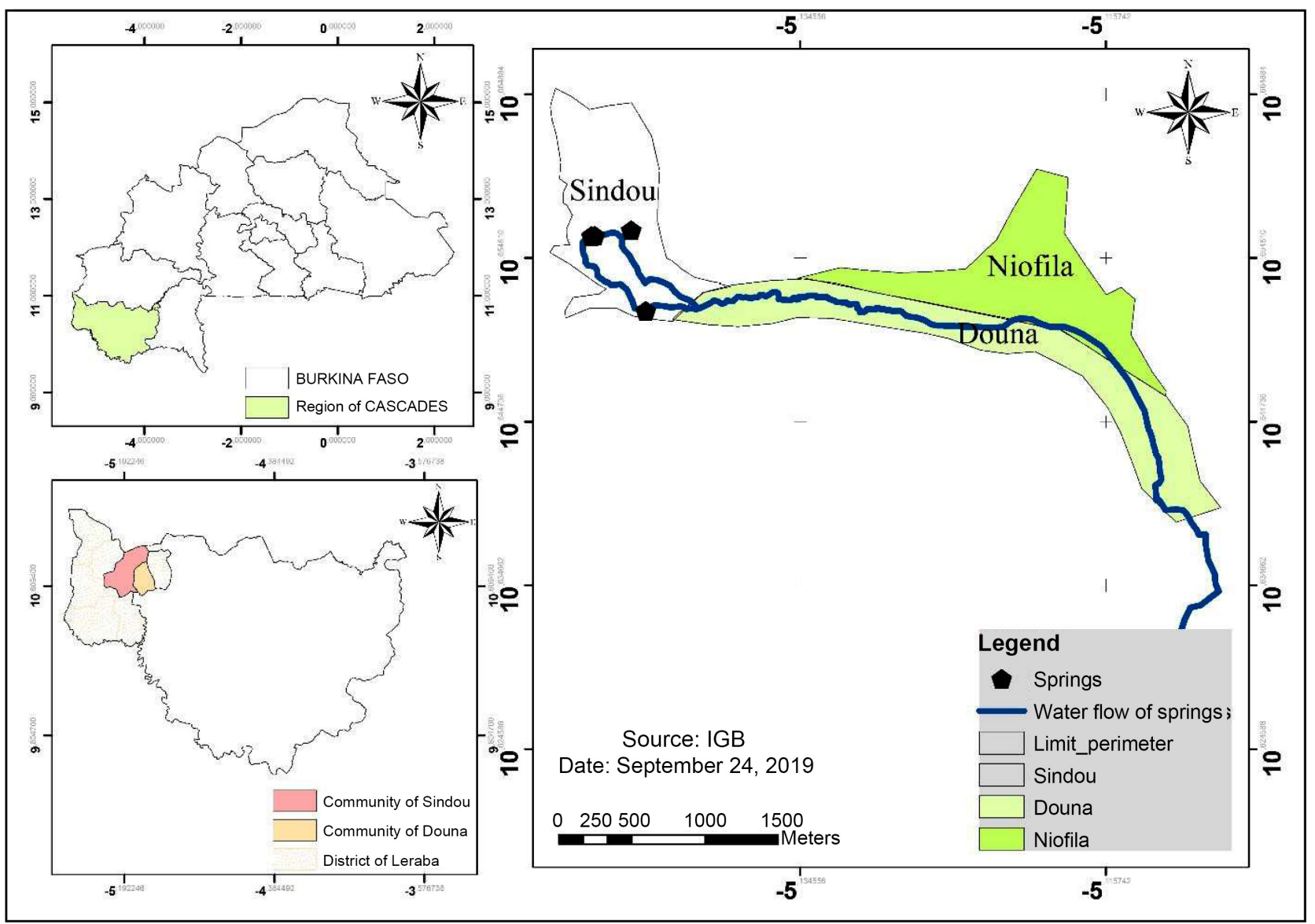

Figure 1. Localization of the Sindou Pic rice perimeter.

\subsection{Determination of Hydrodynamic Parameters of the Soil}

The determination of the different types of soil as well as the useful reserve was made by the double ring method of Muntz. The measurements were taken during the 2019 off-season on 15 points chosen according to the accessibility of the terrain and by zoning the different types of soil with naked eye (Figure 2). The data were processed using Minitab 18 software by applying the least squares method of cumulative infiltration to determine the saturated hydraulic conductivity (Ksat). The Ksat is introduced in the Soil Water Characteristics software for the determination of the types of soils and the characteristic humidities.

\subsection{Characterization of the Vulnerability of the Aquifer to Agricultural Inputs by the DRASTIC Method}

\section{Description}

The DRASTIC method [11] was used in this study because it takes into account most of the hydrogeological factors that affect and control the vertical flow of underground water [12]. The method combines seven parameters considered as vulnerability factors which are: The depth of the water table of the underground water $(D)$, the net recharge $(R)$, the lithological nature of the aquifer (A), the soil texture (S), topography or slope of the ground (T), the impact of the 


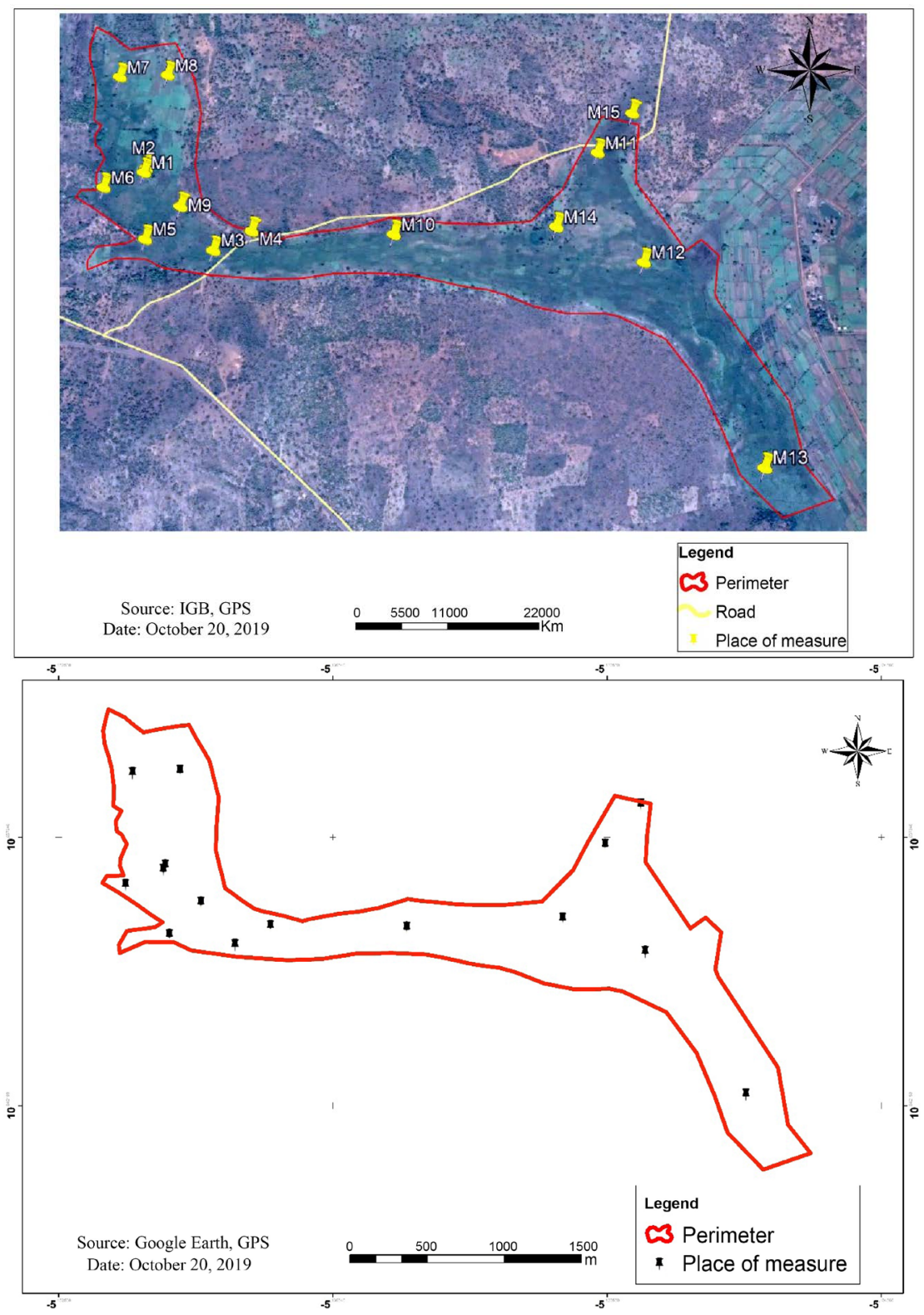

Figure 2. Map of the infiltration measurement points on the Pic of Sindou rice perimeter.

unsaturated zone (I) and the hydraulic conductivity or permeability of the saturated zone (C). Each of these seven parameters has been subdivided into class, indexed by ratings varying from 1 to 10 and assigned a numerical weight between 1 and 5 depending on its degree of influence. The value 1 corresponds to the conditions of lowest vulnerability to pollution and the value 10 to those favoring the highest vulnerability. The final index which characterizes the degree of vulnerability of a given sector of the water table, is the sum of the product of the weights by the associated dimensions of the seven parameters according to the following formula:

DRASTIC (ID) index calculation formula

$$
\mathrm{ID}=\left(D_{w} D_{r}\right)+\left(R_{w} R_{r}\right)+\left(A_{w} A_{r}\right)+\left(S_{w} S_{r}\right)+\left(T_{w} T_{r}\right)+\left(I_{w} I_{r}\right)+\left(C_{w} C_{r}\right)
$$


which: $r=$ rating and $w=$ poids.

According to the value classes of the DRASTIC index obtained, five degrees of vulnerability were defined by [11] ranging from very low to very high vulnerability.

\section{Evaluation of the DRASTIC parameters}

The different vulnerability factors of the DRASTIC method were determined as follows: the depth of the water table thanks to the interpolation of the static levels in the piezometers of the National Office for Water and Sanitation (ONEA). The value of the underground water recharge was calculated by the Thornthwaite method using climatic data from the Karfiguela station. The lithological nature of the aquifer, the unsaturated zone and the soil texture were taken from ONEA drilling logs, the soil map and the result of infiltration measurements on the perimeter to a depth of $50 \mathrm{~cm}$. The slope of the terrain is obtained from the digital terrain model. And, the hydraulic conductivity is chosen according to the permeability of the geological context.

\section{Results}

\subsection{Characterization of the Hydrodynamic Parameters of the Soil}

Analyze shown that soil type in Pic of Sindou rice perimeter is Clay-loam because it represents $40 \%$ of soil against $20 \%$ for loam and $13 \%$ for each of clay, silt-clay-loam, silt-loam (Figure 3).

\subsection{Characterization of Agricultural Inputs}

The survey results show that nearly $85 \%$ of farmers in the Pic of Sindou rice perimeter are not literate. This low literacy rate constitutes a handicap for the rational use of phytosanitary products. The different types of agricultural inputs used on

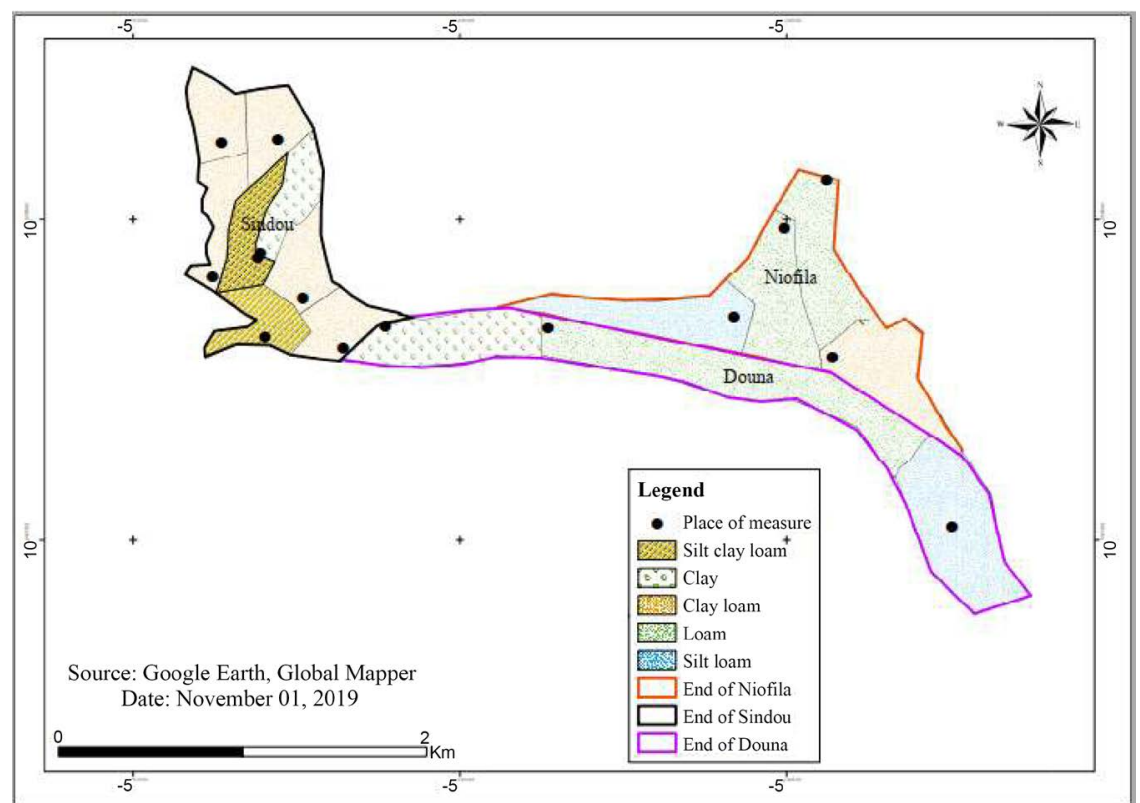

Figure3. Map of the soil of Sindou Pic rice perimeter. 
the Pic of Sindou rice perimeter are NPK and l'Urea at $90 \%$ and $10 \%$ for organic manure (Table 1).

The pesticides used are of five types (Table 2) including four herbicides and one insecticide. The toxicity classes and the active ingredients of each pesticide are listed in (Table 2).

\subsection{Vulnerability of the Underground Resource}

The DRASTIC method shows that $90 \%$ of the area of Pic of Sindou rice perimeter is slightly vulnerable in view of the rice activity that occurs there and the rest of the area (10\%) has a medium vulnerability (Figure 4).

Table 1. Different types of fertilizers listed on the irrigated perimeter.

\begin{tabular}{ccc}
\hline Fertilizer & Quantity in the off-season $(\mathrm{kg})$ & Percent \\
\hline NPK & 6095 & $45.00 \%$ \\
Urea & 6095 & $45.00 \%$ \\
Organic manure & 1355 & $10.00 \%$ \\
Total & 13,545 & $100.00 \%$ \\
\hline
\end{tabular}

Table 2. Different types of pesticides listed on the perimeter.

\begin{tabular}{ccccc}
\hline Pesticides & Nature of pesticides & Toxicity classes (Correspondence) & Active ingredients/dose & Quantity (L/off-season) \\
\hline Douma Woro & Herbicide & II (Moderately hazardous "Harmful”) & Glyphosate 480 g/L & \\
Nwura Wura 480 SL & Herbicide & II (Moderately hazardous "Harmful”) & Glyphosate 480 g/L & 200 \\
Shye Nwura 480 EC & Herbicide & III (Slightly hazardous “Warming”) & Glyphosate $480 \mathrm{~g} / \mathrm{L}$ & 94 \\
Sumitex 400 EC & Insecticide & II (Moderately hazardous "Harmful”) & Dimethoate 400 g/L & 68 \\
Topextra 720 SL & Herbicide & II (Moderately hazardous “Harmful”) & $2.4 \mathrm{D}$ amine salt 720 g/L &
\end{tabular}

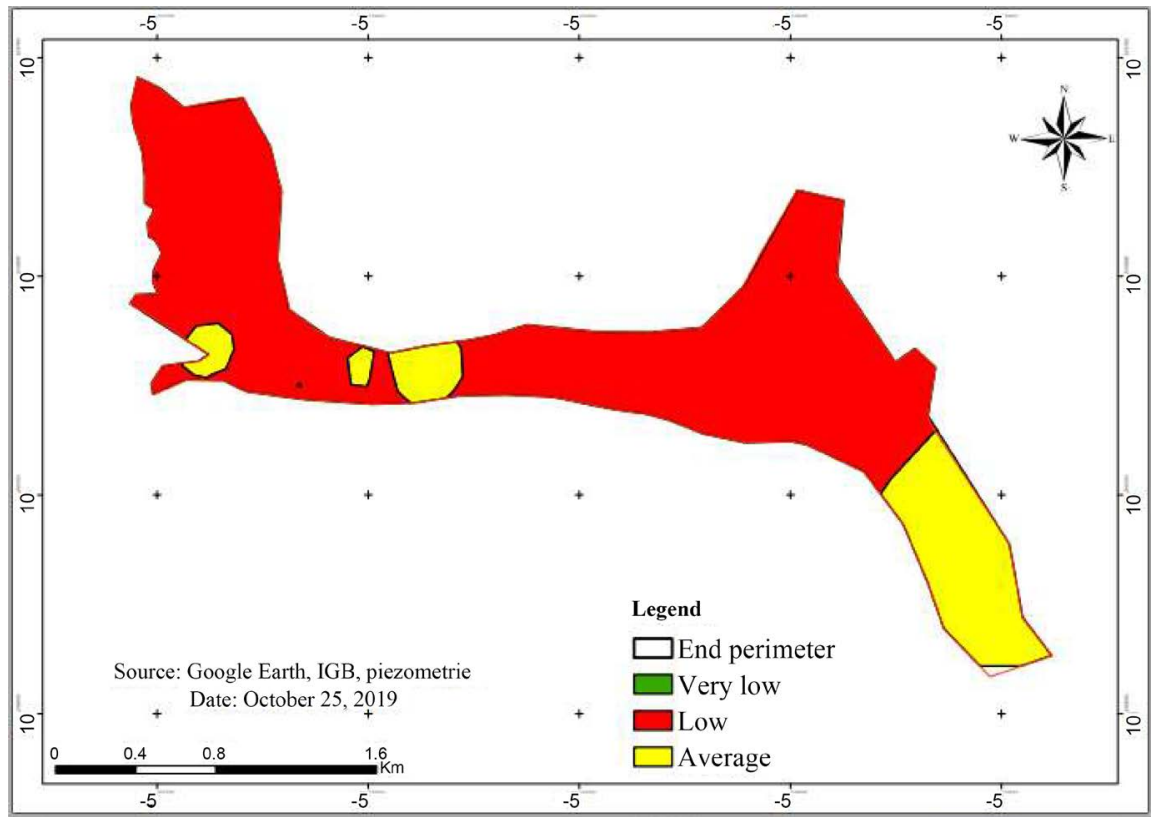

Figure 4. Map of vulnerability to agricultural pollution in the area. 


\section{Discussion}

On the map of vulnerability (Figure 4), the medium vulnerability classes are observed in the four water source area, in the center and in the far southeast of the perimeter. Low vulnerability classes occupy almost the entire area of the perimeter. The dominant soil being of clay-loam type, clay-loam textures constitute a factor limiting the infiltration of pollutants towards the aquifer. However, pesticides accumulate in these clay-rich soils [6] [13], which can pose a long-term toxicity problem. Indeed, the low or medium vulnerability is not static because the contamination process is slow [14] and its effects are very formidable on the groundwater [15]. Although the level of pollution of the aquifer by agricultural inputs is currently low, this vulnerability map has made it possible to identify areas at risk of pollution. In addition, the investigation revealed that after the use of pesticides, their packaging is discarded around the perimeter and sometimes serves as a utensil for taking water. However, for these toxicity classes highlighted by the field survey, the World Health Organization recommends that the use of these products is reserved for trained caterers and who comply with the prescribed precautions.

\section{Conclusion}

The analysis of the impact of agricultural inputs on groundwater pollution in off-season rice growing on the Sindou Pic rice perimeter required the determination of hydrodynamic parameters and the characterization of the vulnerability of the aquifer to agricultural inputs in using the DRASTIC method. The Sindou Pic rice perimeter is dominated by clay-loam. The aquifer's vulnerability to agricultural pollution is low, but the risk of contamination is real.

\section{Acknowledgements}

We express our gratitude to the provincial directorate of the National Office of Water and Sanitation, and the Provincial Directorate of the Ministry of Agriculture of Leraba for their frank collaboration within the framework of this study.

\section{Conflicts of Interest}

The authors declare no conflicts of interest regarding the publication of this paper.

\section{References}

[1] MAH (2010) Recensement général de l'Agriculture (2006-2010). Minsitère de l'Agriculture de l'Hydraulique et des ressources halieutiques, Ouagadougou, Volume $1,61 \mathrm{p}$.

[2] Toé, A.M., Ouédraogo, M., Ouédraogo, R., Ilboudo, S. and Guissou, P.I. (2013) Pilot Study on Agricultural Pesticide Poisoning in Burkina Faso. Interdisciplinary Toxicology, 6, Article ID: 185191. https://doi.org/10.2478/intox-2013-0027

[3] OlinaBassala, J.-P., Dugue, P., Granie, A.-M. and Vunyungah, M. (2015) Pratiques 
agricoles et perceptions paysannes de l'usage des herbicides dans les champs familiaux au nord-Cameroun. International Journal of Advanced Studies and Research in Africa, 6, 94-107.

[4] Aghzar, N., Berdai, H., Bellouti, A. and Soudi, B. (2002) Pollution nitrique des eauxsouterraines au Tadla (Maroc). Journal of Water Science, 15, 459-492.

https://doi.org/10.7202/705465ar

[5] Cheloufi, H. and Jacquin, F. (2003) Influence du pedoclimat sur l'évolution des composes azotes présents dans les sols lorraines: Conséquence sur la qualité des eaux. Bulletin de 1 Académie Lorraine des Sciences, 42, 1-4.

[6] Sawadogo, P.W. (2006) Variation de la teneur en résidus de pesticides dans les sols de la zone cotonnière du BurkinaFaso. Journal Africain des Sciences de P environnement, 1, 29-39.

[7] Laurant, F. (2015) L'évolution des pratiques agricoles face aux enjeux de la qualité de l'eau: Le bassin de l'Oudon (France). Territoire en mouvement Revue de géographie et aménagement, 25-26. https://doi.org/10.4000/tem.2745

[8] Alami, I.I., Zeraouli, M., Addou, M., Okhtari, A. and Soulaymani, A. (2007) Évaluation de la pollution nitrique de la nappe phréatique de la zone côtière du Gharb (M'nasra) au Maroc entre 1993 et 2003. Revue Afrique Science, 3, 378-390.

[9] Bettahar, N., Benamara, A.A., Kettab, A. and Douaoui, A. (2009) Risque de pollution nitratée des zones semi-arides: Cas de la vallée du moyen Cheliff occidental (Nord Algérien). Journal of Water Science, 22, 69-78. https://doi.org/10.7202/019824ar

[10] COWI (2012) Etat des lieux des ressources en eau du bassin de la Comoé. Ouagadougou, Version Finale, 353 p.

[11] Aller, L., Bennet, T., Lehr, J.H., Petty, R.J. and Hacke, G. (1987) DRASTIC: A Standardized System for Evaluating Groundwater Pollution Potential Using Hydrogeological Settings. National Ater Well Association 1987, Rapport EPA-600/2-87-035, $622 \mathrm{p}$.

[12] Kouame Kan Jean (2007) Contribution à la Gestion Intégrée des Ressources en Eaux (GIRE) du District d'Abidjan (Sud de la Côte d'Ivoire): Outils d'aide à la décision pour la prévention et la protection des eaux souterraines contre la pollution. Thèse de doctorat, Université de Cocody, Cocody.

[13] Nonguierma, G.B. (2006) Contribution à l'évaluation des effets de l'utilisation des pesticides en production maraichère dans la plaine périurbaine de Boulmiougou Ouagadougou. Mémoire de licence professionnelle en génie de l'environnement. Université de Ouagadougou, Ouagadougou.

[14] Baghvand, A., Nasrabadi, T., Nabibidhendi, G., Vosoogh, A., Karbassi, A. and Mehradadi, N. (2010) Groundwater Quality Degradation of an Aquifer in Iran Central Desert. Desalination, 260, 264-275. https://doi.org/10.1016/j.desal.2010.02.038

[15] Jourda, J.P., Saley, M.B., Kouame, K.J., Kouadio, B.H., Biemi, J. and Razack, M. (2005) Gestion et protection des ressources en eauxsouterraines: Contribution d'un SIG à la réalisation de la carte devulnérabilité à la pollution des aquifères fissurés de Korhogo (Nord de laCôte d'Ivoire) selon la méthode DRASTIC. Actes de la conférence francophone SIG 2005, Paris, du 5 au 6 octobre, 16 p. 